\title{
Tanshinone IIA inhibits Hep-J5 cells by increasing calreticulin, caspase 12 and GADD153 protein expression
}

\author{
CHUN-YUAN CHENG ${ }^{1,2}$ and CHIN-CHENG SU ${ }^{3,4}$ \\ ${ }^{1}$ Institute of Medicine, Chung Shan Medical University, Taichung 40201; ${ }^{2}$ Changhua Christian Hospital, Changhua 500; \\ ${ }^{3}$ Institute of Pharmacology and Toxicology, Tzu-Chi University; ${ }^{4}$ Division of General Surgery, \\ Buddhist Tzu-Chi General Hospital, Hualien 97004, Taiwan, R.O.C.
}

Received March 10,2010; Accepted May 31, 2010

DOI: 10.3892/ijmm_00000476

\begin{abstract}
Tanshinone IIA (Tan-IIA) is extracted from Danshen, Salviae miltiorrhizae Radix, which has been widely adopted in traditional herbal medicine to treat cardiovascular and hepatic diseases. Tan-IIA induces apoptosis and inhibits proliferation in human hepatocellular carcinoma (HCC) cells. However, the molecular mechanisms of Tan-IIA on human HCC cells are not understood clearly. In the present study, the cytotoxicity of Tan-IIA as well as its molecular mechanisms in human HCC J5 cells was investigated. The cytotoxicity was assayed by MTT. The protein expression of p53, p21, Bax, Bcl-2, Cdc25c, Cdc2, calreticulin, caspase 12, GADD153, caspase 3 and $B$-actin in $\mathrm{J} 5$ cells were determined by Western blotting. The cell cycles were analyzed by FACS. The protein expression of caspase 12, GADD1533 and caspase 3 were detected by immunocytochemical staining. The results showed that Tan-IIA inhibited J5 cells in a dose- and timedependent manner. The protein expression of p53, p21, Bax, calreticulin, caspase 12, caspase 3 and GADD153 were increased, but $\mathrm{Bcl}-2, \mathrm{Cdc} 25 \mathrm{c}$ and $\mathrm{Cdc} 2$ were decreased in $\mathrm{J} 5$ cells. In addition, the results also showed that Tan-IIA arrested $\mathrm{J} 5$ cells in the G2/M phase. Immunocytochemistry staining showed that J5 cells treated with Tan-IIA up-regulated the protein expression of caspase 12, 3 and GADD153. Taken together, the findings suggest that Tan-IIA inhibits and induces apoptosis in J5 cells through novel molecular targets, calreticulin, caspase 12 and GADD153.
\end{abstract}

\section{Introduction}

Hepatocellular carcinoma (HCC) is the fifth most prevalent cancer in men in the world (1). According to a 2007 report from the 'People's Health Bureau of Taiwan' HCC is the leading cause of cancer related deaths in men $(41.4 / 100,000)$ in Taiwan

Correspondence to: Dr Chin-Cheng Su, Division of General Surgery, Buddhist Tzu Chi General Hospital, 707, Sec.3, ChungYang Road, Hualien City 970, Taiwan, R.O.C.

E-mail:succ.maeva@msa.hinet.net

Key words: tanshinone IIA, J5 cells, calreticulin, caspase 12, GADD153
(2). HCC is chemo-resistant to many of the available chemotherapeutic agents (such as 5-fluorouracil, doxorubicin and cisplatin) (3). Because of serious limitations of the surgical and medical treatment available, an ongoing need for more effective chemotherapeutic agents exists for HCC. The endoplasmic reticulum (ER) stress-induced apoptotic pathway has been suggested to be least affected by the resistance mechanisms, becoming a potential target of chemotherapeutic strategy (4). Tanshinone IIA (Tan-IIA; C19H18O3) was extracted from Danshen, Salviae Miltiorrhizae Radix $(5,6)$. It has been well documented that Tan-IIA possesses antioxidant properties $(7,8)$, anti-inflammatory activities $(9,10)$ and anti-tumor activity in many human cancer cells (11-13). Our previous studies showed that Tan-IIA induces apoptosis and inhibits proliferation in human lung cancer A549 cells through the induction of ROS and a higher ratio of Bax/Bcl-2 (14). Growth inhibition and apoptosis induction of Tan-IIA on human hepatocellular carcinoma cells are well documented (15-17). However, the molecular mechanisms that cause Tan-IIA to induce apoptosis in human hepatocellular carcinomas via interaction of ER stress have not been clarified. In the present study, we investigated the effects of Tan-IIA in human hepatocellular carcinoma J5 cells.

\section{Materials and methods}

Chemicals and reagents. Fetal bovine serum (FBS), sodium pyruvate, HEPES, dimethyl sulfoxide (DMSO), RPMI-1640, MTT, trypsin-EDTA, mouse anti- $\beta$-actin, Cdc25c and penicillin-streptomycin were obtained from Sigma-Aldrich (St. Louis, MO, USA), 10x TG-SDS buffers, Tris, Tween-20, SDS and glycine were obtained from Amresco (St. Louis, MO, USA). BioMax Film was obtained from Kodak. Mouse anti-caspase 12 and $\mathrm{Cdc} 2$ were obtained from Abcam. Mouse anti-caspase 3 was obtained from R\&D (Minneapolis, MN, USA), and rabbit anti-Bcl-2 and calreticulin from Cell Signaling Technology.

Cell culture. The human hepatocellular carcinoma J5 cell line was kindly provided by Dr H.J. Harn (Graduate Institute of Cancer Biology and Center for Molecular Medicine, China Medical University and Hospital, Taichung, Taiwan).

J5 cells were maintained with RPMI-1640 medium containing $10 \% \mathrm{FBS}, 1 \%$ penicillin-streptomycin $(10,000 \mathrm{U} / \mathrm{ml}$ 
penicillin; $10 \mathrm{mg} / \mathrm{ml}$ streptomycin) at $37^{\circ} \mathrm{C}$ humidified atmosphere containing $5 \% \mathrm{CO}_{2}$.

Cell proliferation assay. Viability was evaluated by MTT assay in triplicate (18). Briefly, J5 cells were plated in 96-well plates at a density of $2 \times 10^{4}$ cells/well and allowed to adhere and grow for $24 \mathrm{~h}$. J5 cells were treated with various concentrations $(0,1,2.5,5,10$, and $20 \mu \mathrm{g} / \mathrm{ml})$ of Tan-IIA for different durations $(24,48$ and $72 \mathrm{~h})$, then $100 \mu 1$ of $1 \mathrm{mg} / \mathrm{ml}$ 3-(4,5-dimethylthiazol-2-yl)-2,5-diphenyl-2H-tetrazolium bromide (MTT) was added and incubated for $2 \mathrm{~h}$ at $37^{\circ} \mathrm{C}$. Subsequently, the medium was removed and $100 \mu 1$ DMSO was added to the wells. Absorbance was measured using an ELISA plate reader at $590 \mathrm{~nm}$. Data were calculated as the percentage of proliferation, using the following formula: Proliferation rate $(\%)=\left(\mathrm{OD}_{\text {test }}-\mathrm{OD}_{\text {blank }}\right) \times 100$, where $\mathrm{OD}_{\text {test }}$ and $\mathrm{OD}_{\text {blank }}$ are the optical density of the test substances and the blank control, respectively.

Protein preparation. Approximately $1 \times 10^{6}$ cells $/ 10-\mathrm{cm}$ dish were incubated with various concentrations of Tan-IIA $(0,1$, 2.5 and $5 \mu \mathrm{g} / \mathrm{ml}$ ) for $24 \mathrm{~h}$ before cells were harvested by centrifugation. Protein was extracted as described previously (19). Briefly, cells cultured in 10-cm dishes were washed twice with ice-cold PBS and lyses in $100 \mu 1$ of lyses buffer (Pro-Prep buffer, Intron). After incubation on ice for $40 \mathrm{~min}$, cell lysates were centrifuged and then supernatants were collected. Protein concentrations were measured using the Bradford method (20).

Western blotting. Western blot analysis was conducted using antibody against caspase $3, \mathrm{Cdc} 25 \mathrm{c}, \mathrm{Cdc} 2$, caspase $12, \mathrm{CHOP}$, $\mathrm{Bcl}-2$, Calreticulin and $\mathrm{B}$-actin (internal controls) to determine loading efficiency. Protein samples containing $40 \mu \mathrm{g}$ of protein were separated on 10-15\% SDS-polyacrylamide gels and transferred to immobilon polyvinylidene difluoride membranes (Millipore). Membranes were incubated in TBST buffer (0.1 M Tris- $\mathrm{HCl}$ (pH 7.4), $0.9 \% \mathrm{NaCl}, 0.1 \%$ Tween-20) supplemented with $5 \%$ dry non-fat milk for $1 \mathrm{~h}$ to block nonspecific binding. After incubated with primary Abs, the membranes were washed thrice with TBST buffer followed by incubation with appropriate streptavidin-HRP-conjugated secondary Abs. The immunoreactive bands were visualized with an enhanced chemiluminescence (ECL, Millipore Corporation) detection kit. Immunoreactive bands were scanned (GS-800; Bio-Rad Life Sciences, Hercules, CA, USA) and analyzed using a digital scanning densitometer (Quantity One, v4.4.0; Bio-Rad Life Sciences).

Cell cycle analysis. Cell cycle analysis was performed as stated previously (21). Briefly, J5 cells were treated with various concentrations $(0,1,2.5$ and $5 \mu \mathrm{g} / \mathrm{ml})$ of Tan-IIA for $24 \mathrm{~h}$. Cells were harvested and washed with PBS, and then resuspended in $70 \%$ ethanol at $-20^{\circ} \mathrm{C}$ overnight. Cells were washed thrice with PBS and stained with $20 \mu \mathrm{g} / \mathrm{ml}$ propidium iodide (PI). DNA content was analyzed on a cytofluorimeter by fluorescence-activated cell sorting analysis (FACScan, Becton Dickinson Co., San Jose, CA) and ModFit software (Verity Software House, Turramurra, NSW, Australia). J5 cells were treated with Tan-IIA $(2.5 \mu \mathrm{g} / \mathrm{ml})$ for different

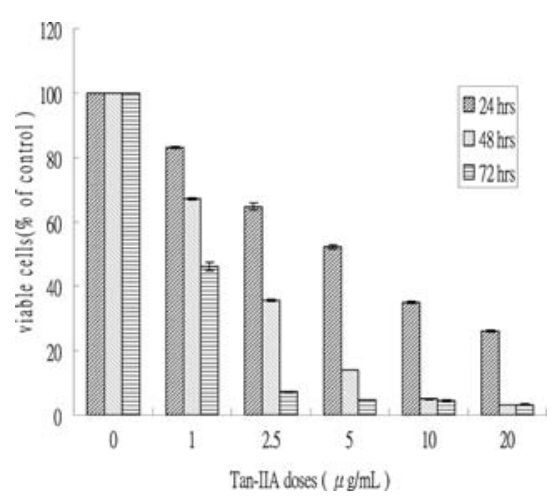

Figure 1. Cytotoxicity of Tanshinone IIA (Tan-IIA) in J5 cells. The cytotoxicity of Tan-IIA in J5 cells was determined using the MTT assay as described in Materials and methods. Tan-IIA significantly inhibited J5 cell growth in a time- and dose-dependent manner. Each point is the mean $\pm \mathrm{SD}$ of three experiments. ${ }^{*} \mathrm{P}<0.05$ with respect to control.

durations $(24,48$ and $72 \mathrm{~h})$, then cells were harvested and washed in PBS, and resuspended in $70 \%$ ethanol at $-20^{\circ} \mathrm{C}$ overnight. Cells were washed thrice with PBS and stained with $20 \mu \mathrm{g} / \mathrm{ml}$ PI. DNA content was analyzed on a cytofluorimeter by fluorescence-activated cell sorting analysis (FACScan, Becton Dickinson Co.) and ModFit software (Verity Software House).

Immunocytochemistry. Immunocytochemistry analysis procedures were described previously (22). Briefly, J5 cells were treated with or without Tan-IIA $(2.5 \mu \mathrm{g} / \mathrm{ml})$ for $24 \mathrm{~h}$, and then fixed by $4 \%$ paraformaldehyde to allow the detection of anti-caspase 3, caspase 12 and GADD153 antibody (1:200, Cell Signaling Technology), and then FITC-conjugated secondary antibody $(1: 1,000$, Chemicon). Cells were observed with fluorescent microscopy (Zeiss Axioskop 2 plus).

J5 cells were treated with Tan-IIA $(2.5 \mu \mathrm{g} / \mathrm{ml})$ for $24 \mathrm{~h}$, then washed with PBS twice. J5 cells were fixed in $4 \%$ paraformaldehyde solution for $1 \mathrm{~h}$, then washed with PBS again and then stained with PI $(5 \mu \mathrm{g} / \mathrm{ml})$ and/or with DAPI $(0.4 \mu \mathrm{g} / \mathrm{ml})$ for $10 \mathrm{~min}$ in the dark. Cells were covered with PBS and observed with fluorescent microscopy.

Inhibition of the effect of caspase 12 by Z-VAD-FMK. Hep-J5 cells were pretreated with or without caspase 12 inhibitor Z-VAD-FMK $(50 \mu \mathrm{M})$ for $1 \mathrm{~h}$, then treated with or without Tan-IIA $(2.5 \mu \mathrm{g} / \mathrm{ml})$ for $24 \mathrm{~h}$. Cell viability was determined with MTT assay as previously described (18).

Statistical analysis. Values are presented as the mean \pm SD. Student's t-test was used to analyze statistical significance. A P-value $<0.05$ was considered statistically significant for all tests.

\section{Results}

Cytotoxicity of Tan-IIA in J5 cells. J5 cells were exposed to various concentrations of Tan-IIA of $0,1,2.5,5,10$ and $20 \mu \mathrm{g} / \mathrm{ml}$ for $24 \mathrm{~h}$. Viable cell percentages relative to control were $82.94 \pm 0.31,64.71 \pm 1.15,52.14 \pm 0.69,34.99 \pm 0.35$ and 
A
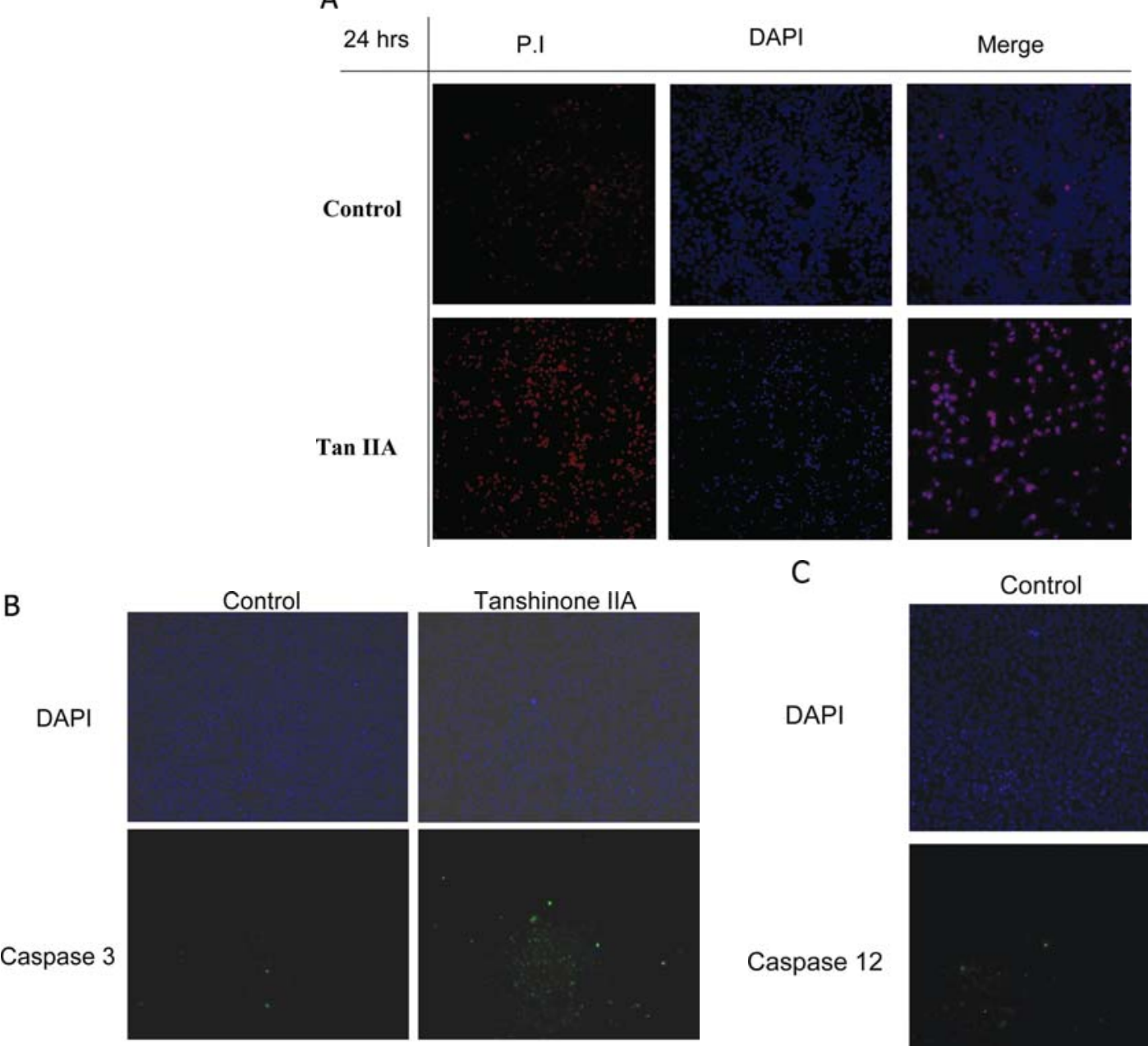

$100 x$

D

DAPI

GADD153

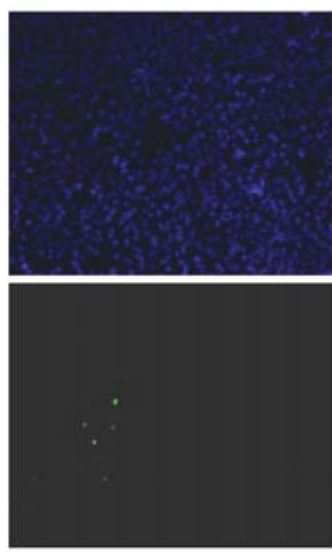

$100 X$
Tanshinone IIA

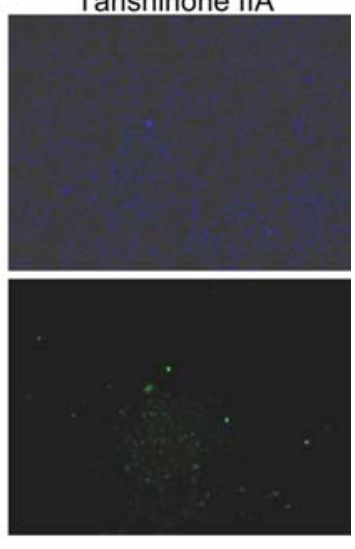

$100 \mathrm{X}$

Tanshinone IIA

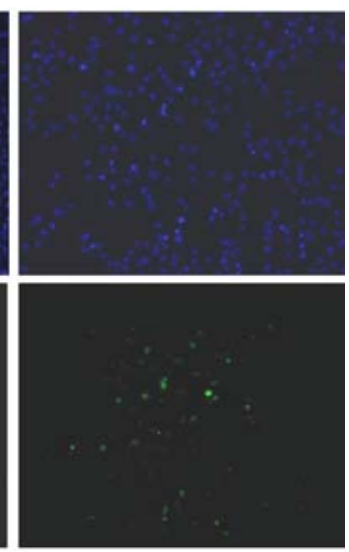

$100 \mathrm{X}$
C

DAPI

\section{Caspase 12}

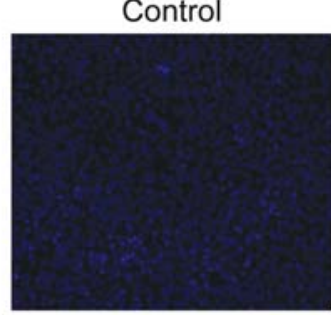

Tanshinone IIA

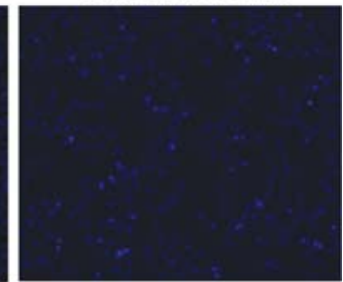

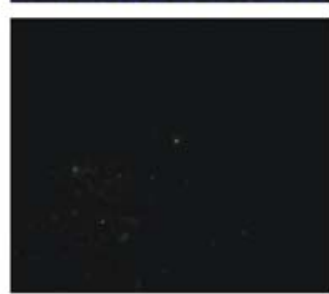

$100 x$

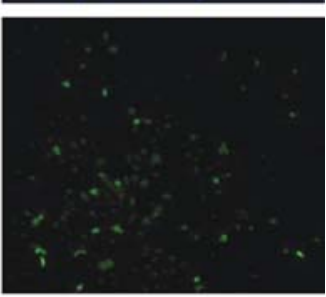

$100 x$
Figure 2. Apoptotic effect of Tan-IIA in J5 cells. J5 cells were treated with or without Tan-IIA $(2.5 \mu \mathrm{g} / \mathrm{ml})$ for $24 \mathrm{~h}$, then stained with propidium iodide (PI), DAPI and merge (both PI and DAPI), and observed by fluorescent microscopy. Color staining for PI was red, DAPI was blue, and the merge was purple (A). J5 cells were treated with Tan-IIA for $24 \mathrm{~h}$, then stained with antibodies (caspase 12, GADD153 and caspase 3). The results showed J5 cells treated with Tan-IIA increased the expression of caspase 3 (B), caspase 12 (C) and GADD153 (D) compared to the control group. This shows that Tan-II A can induce apoptosis in J5 cells through up-regulating the protein expression of caspase 12 and GADD153.
$26.04 \pm 0.3 \%$, respectively. J5 cells were exposed to Tan-IIA at $0,1,2.5,5,10$ and $20 \mu \mathrm{g} / \mathrm{ml}$ for $48 \mathrm{~h}$. Viable cell percentages relative to control were $67.07 \pm 0.37,35.69 \pm 0.32$, $13.99 \pm 0.09,4.96 \pm 0.11$ and $3.15 \pm 0.07 \%$, respectively. J5 cells were exposed to Tan-IIA at $0,1,2.5,5,10$ and $20 \mu \mathrm{g} / \mathrm{ml}$ for $72 \mathrm{~h}$. Viable cell percentages relative to control were $46.04 \pm 1.24,7.21 \pm 0.08,4.67 \pm 0.04,4.57 \pm 0.28$ and $3.34 \pm 0.07 \%$, respectively. The results show that the cytotoxicity of Tan-IIA in $\mathrm{J} 5$ cells decreases in a dose- and time-dependent manner
(Fig. 1). The half maximal inhibitory concentration $\left(\mathrm{IC}_{50}\right)$ for 24,48 and $72 \mathrm{~h}$ was $5.62,1.81$ and $0.93 \mu \mathrm{g} / \mathrm{ml}$, respectively.

Tan-IIA induces apoptosis in J5 cells. The apoptotic effect of Tan-IIA in J5 cells was determined by immunocytochemistry. Cells were treated with or without Tan-IIA $(2.5 \mu \mathrm{g} / \mathrm{ml})$ for $24 \mathrm{~h}$, then stained with PI, DAPI and merge (both PI and DAPI). Then J5 cells were observed with fluorescent microscopy. J5 cells stained with PI were red, DAPI were blue, and 
A
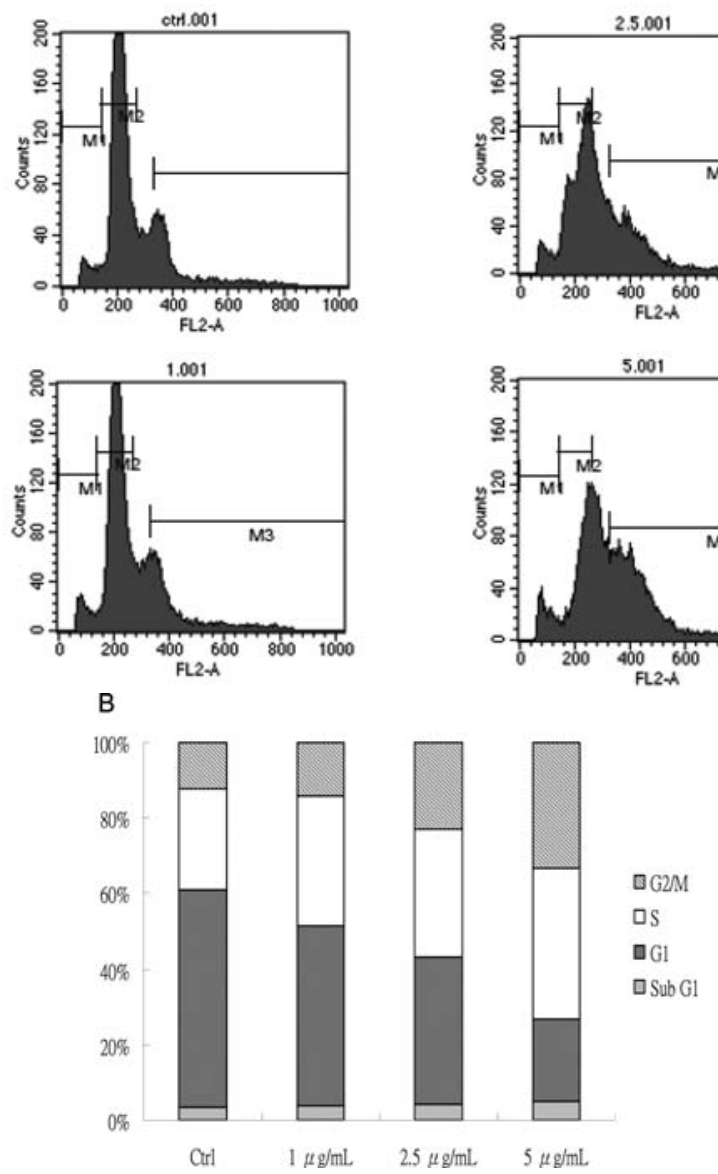

C
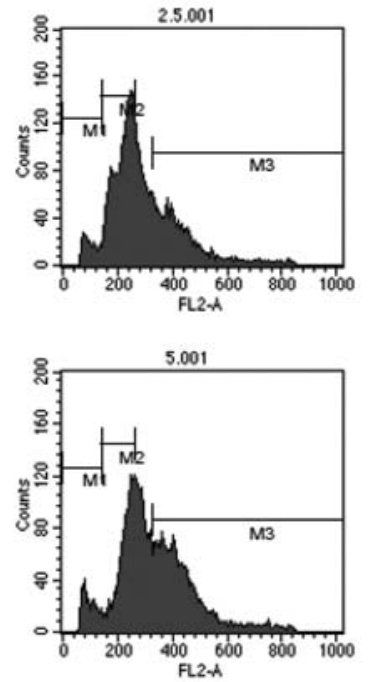
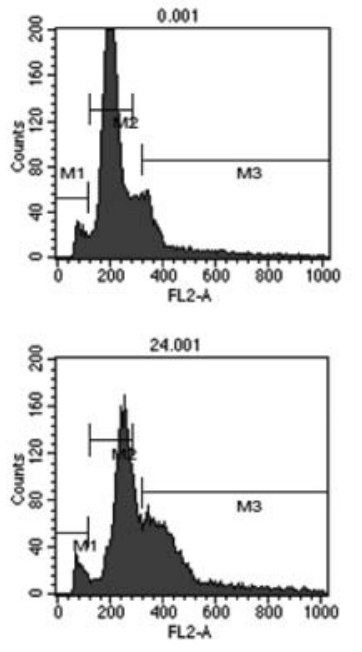
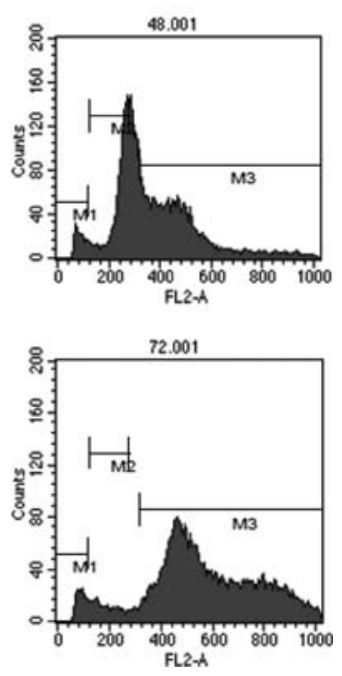

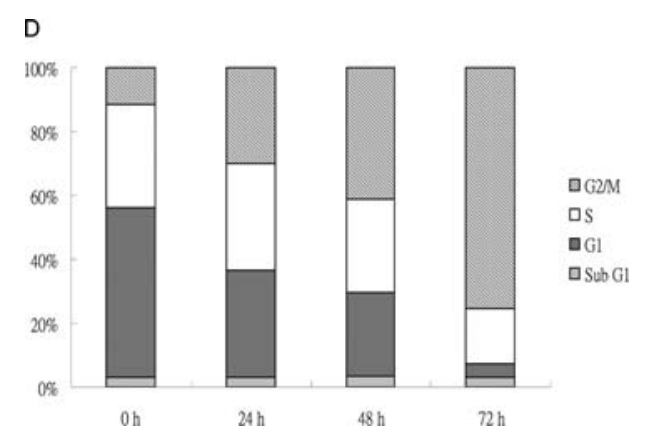

Figure 3. Cell cycle effect of Tan-II A in J5 cells. J5 cells were treated with various concentrations of Tan-IIA ( $0,1,2.5$ and $5 \mu \mathrm{g} / \mathrm{ml})$ for $24 \mathrm{~h}$ and then stained with $10 \mu \mathrm{g} / \mathrm{ml}$ propidium iodide. The cell cycle was determined by FACS assay as described in Materials and methods. The results showed J5 cells treated with Tan-IIA arrest in G2/M phase (A and B). J5 cells were treated with Tan-IIA $(2.5 \mu \mathrm{g} / \mathrm{ml})$ for different durations $(24,48$ and $72 \mathrm{~h})$, and then stained with $10 \mu \mathrm{g} / \mathrm{ml}$ propidium iodide. The cell cycle was determined by FACS assay as described in Materials and methods. The results showed J5 cells treated with Tan-IIA arrest in $\mathrm{G} 2 / \mathrm{M}$ phase $(\mathrm{C}$ and $\mathrm{D})$

merge were purple (Fig. 2A). The results show that Tan-IIA induced apoptosis.

J5 cells were treated with or without Tan-II A $(2.5 \mu \mathrm{g} / \mathrm{ml})$ for $24 \mathrm{~h}$, then J5 cells were stained with DAPI and caspase 3. J5 cells were observed with fluorescent microscopy. We found that J5 cells treated with Tan-IIA significantly increased caspase 3 espression as observed with DAPI staining (Fig. 2B). These results also suggest that Tan-II A induces apoptosis in J5 cells.

J5 cells were treated with or without Tan-IIA $(2.5 \mu \mathrm{g} / \mathrm{ml})$ for $24 \mathrm{~h}$, then stained with caspase 12 and GADD153. Then J5 cells were observed with fluorescent microscopy. Tan-IIA increased the presentation of caspase 12 (Fig. 2C) and GADD153 (Fig. 2D) compared with the control group. These results suggest that Tan-IIA induces ER stress in J5 cells.

Tan-IIA induced J5 cell arrest at G2/M phase. J5 cells were treated with various concentrations of Tan-IIA $(0,1,2.5$ and $5 \mu \mathrm{g} / \mathrm{ml}$ ) for $24 \mathrm{~h}$. Then the cell cycle was examined by flow cytometry. The results showed that Tan-IIA induced J5 cell arrest at the G2/M phase (Fig. 3A and B). Hep-J5 cells were treated with Tan-IIA $(2.5 \mu \mathrm{g} / \mathrm{ml})$ for different durations (24, 48 and $72 \mathrm{~h}$ ), and then the cell cycle was examined with flow cytometry. Tan-IIA also induced J5 cell arrest at the G2/M

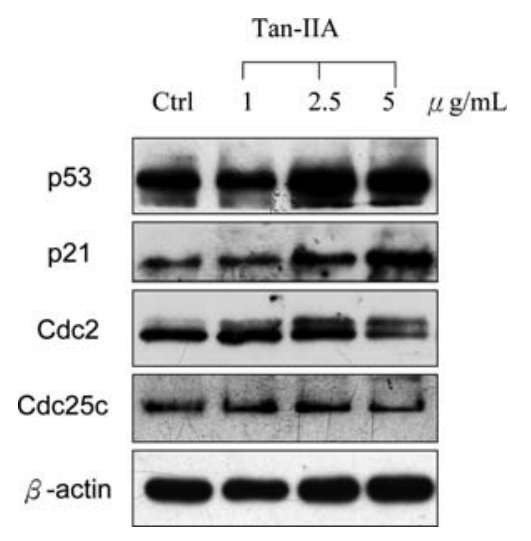

Figure 4. Protein expression of P53, P21, Cdc25c and Cdc2 in Hep-J5. The $\mathrm{G} 2 / \mathrm{M}$ phase check-point associated protein expression in $\mathrm{J} 5$ cells treated with Tan-IIA for $24 \mathrm{~h}$ were measured with Western blotting as described in Materials and methods. J5 cells were treated with Tan-IIA for $24 \mathrm{~h}$ decreased $\mathrm{Cdc} 25 \mathrm{c}$ and $\mathrm{Cdc} 2$ expression but increased P53 and P21 expression.

phase (Fig. 3C and D). Tan-IIA induced J5 cell arrest at the $\mathrm{G} 2 / \mathrm{M}$ phase in a time- and dose-dependent manner. In addition, J5 cells were treated with Tan-IIA. The cell cycles associated with protein expression such as P53, P21, Cdc2 and 
A

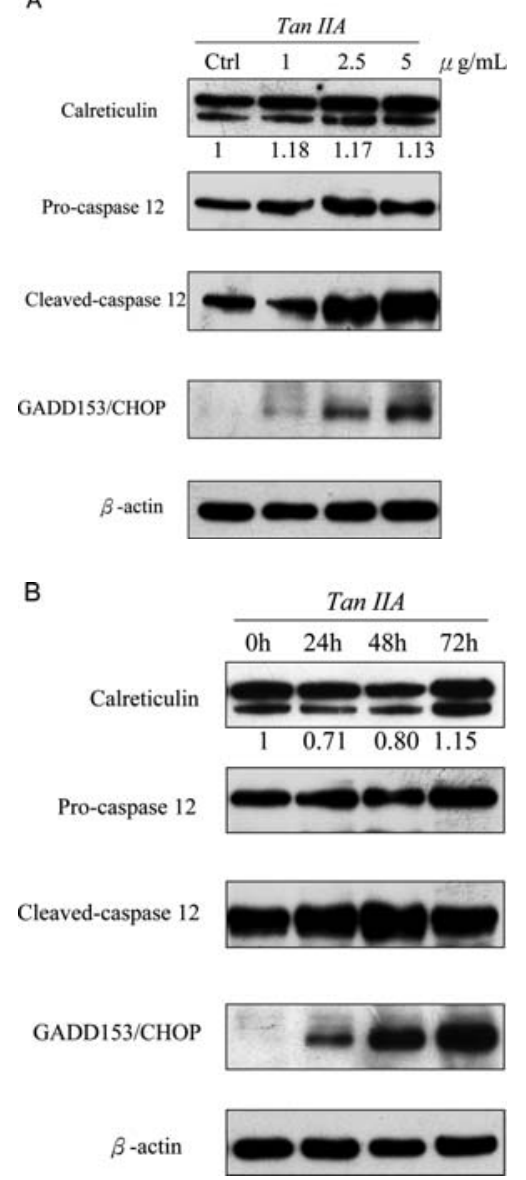

Figure 5. Effects of ER stress associated proteins in Hep-J5 cells. (A) J5 cells were treated with various concentrations of Tan-IIA $(0,1,2.5$ and $5 \mu \mathrm{g} / \mathrm{ml})$ for $24 \mathrm{~h}$. The protein expression of calreticulin, caspase-12, GADD153, Bcl-2 and caspase 3 were measured by Western blotting as described in Materials and methods. (B) J5 cells were treated with Tan-IIA $(2.5 \mu \mathrm{g} / \mathrm{ml})$ for different durations (24, 48 and $72 \mathrm{~h}$ ), and then the protein expression of calreticulin, caspase-12 and GADD153 were measured by Western blotting as described in Materials and methods. Tan-IIA increased the protein expression of calreticulin, caspase-12 and GADD153 in dose- (A) and time- (B) dependent manner.

Cdc25c in $\mathrm{J} 5$ cells were measured by Western blotting. The results show that the protein expression of p53 and P21 were up-regulated but the protein expression of $\mathrm{Cdc} 2$ and $\mathrm{Cdc} 25 \mathrm{c}$ were down-regulated in J5 cells (Fig. 4).

Tan-IIA induces ER stress through Calreticulin and caspase 12 in J5 cells. J5 cells were treated with various concentrations of Tan-IIA $(0,1,2.5$ and $5 \mu \mathrm{g} / \mathrm{ml})$ for $24 \mathrm{~h}$, then examined by Western blotting. The results show that Tan-IIA up-regulated calreticulin and cleavage pro-caspase 12 expression, and then stimulated downstream GADD153 increasing in J5 cells (Fig. 5A). Hep-J5 cells were treated with Tan-IIA $(2.5 \mu \mathrm{g} / \mathrm{ml})$ for different durations $(24,48$ and $72 \mathrm{~h})$, then examined by Western blotting. The results show that Tan-IIA up-regulated calreticulin and the cleavage of pro-caspase 12 expression, and then stimulated downstream GADD153 in J5 cells (Fig. 5B). The results also show that J5 cells treated with Tan-IIA induced GADD153 overexpression suggesting that Tan-IIA induces ER stress in J5 cells.
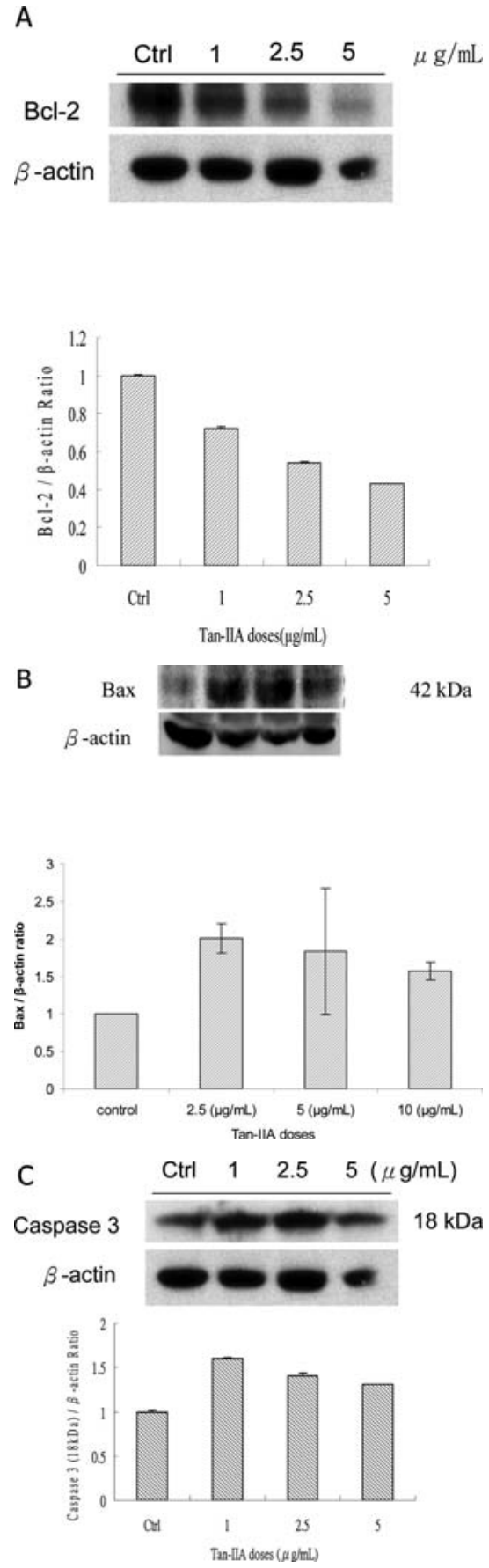

Figure 6. The protein expression of Bax, Bcl-2 and caspase 3 in Hep-J5 cells. (A) J5 cells were treated with various concentrations of Tan-IIA $(0,1$, 2.5 and $5 \mu \mathrm{g} / \mathrm{ml}$ ) for $24 \mathrm{~h}$. The protein expression of Bcl-2 and caspase 3 were measured by Western blotting as described in Materials and methods. (B) J5 cells were treated with various concentrations of Tan-IIA $(0,2.5,5$ and $10 \mu \mathrm{g} / \mathrm{ml}$ ) for $24 \mathrm{~h}$. The protein expression of Bax was measured by Western blotting as described in Materials and methods. Tan-IIA increased caspase 3 (A) and Bax (B), but decrease Bcl-2 (C) expression.

Tan-IIA induces apoptosis through mitochondrial dysfunction. The protein expression of Bax, Bcl-2 and caspase 3 in $\mathrm{J} 5$ cells treated with Tan-IIA were measured by Western blotting. Tan-IIA decreased the protein expression of Bcl-2 (Fig. 6A) but increased Bax (Fig. 6B) and caspase 3 expression (Fig. $6 \mathrm{C})$ in J5 cells. These results suggest that Tan-IIA destroys the mitochondrion function of J5 cells to induce apoptosis. 


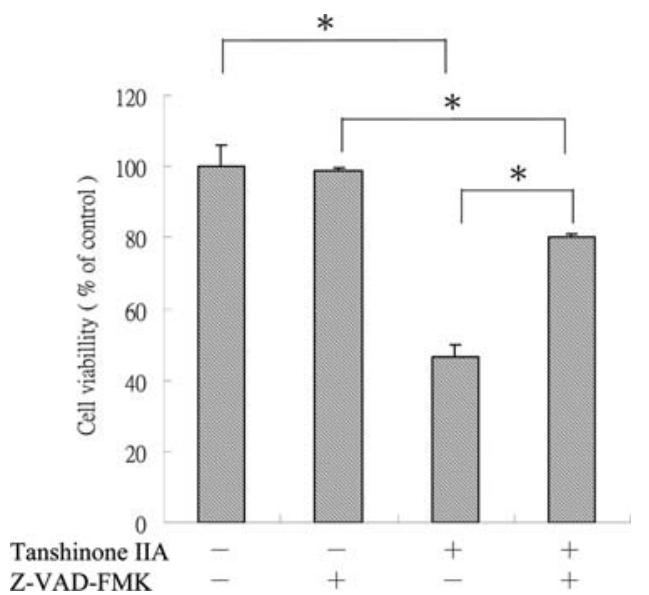

Figure 7. The effects of caspase inhibitor Z-VAD-FMK. J5 cells were pretreated with the caspase inhibitor Z-VAD-FMK $(50 \mu \mathrm{M})$ for $1 \mathrm{~h}$, then treated with Tan-IIA $(2.5 \mu \mathrm{g} / \mathrm{ml})$ for $24 \mathrm{~h}$. Cell viability was determined by MTT assay as described in Materials and methods. J5 cells were treated with both Tan-IIA and Z-VAD-FMK. Viable cells increased significantly compared to Tan-IIA alone. Each point is the mean $\pm \mathrm{SD}$ of three experiments. ${ }^{*} \mathrm{P}<0.05$ with respect to control.

Inhibition of the effect of caspase 12 by Z-VAD-FMK. Hep-J5 cells were pretreated with caspase 12 inhibitor Z-VADFMK $(50 \mu \mathrm{M})$ for $1 \mathrm{~h}$, then $\mathrm{J} 5$ cells were treated with or without Tan-IIA $(2.5 \mu \mathrm{g} / \mathrm{ml})$ for $24 \mathrm{~h}$. The viability of J5 cells was determined by MTT assay. The viable cell percentages of J5 cells treated with Tan-IIA and Z-VAD-FMK increased significantly when compared to J5 cells treated with Tan-IIA alone (Fig. 7). J5 cells pretreated with Z-VADFMK $(50 \mu \mathrm{M})$ decreased the cytotoxicity of Tan-IIA in J5 cells. The results show that one of the molecular mechanisms for Tan-IIA to inhibit J5 cells may be through increasing caspase 12 expression.

\section{Discussion}

In the present study the results show that Tan-IIA induced apoptosis and inhibited Hep-J5 cells in a time- and dosedependent manner. Tan-IIA increased the protein expression of P53, P21 and Bax, but decreased Bcl-2 expression. These results are in agreement with previous studies (15). Our results show that Tan-IIA down-regulated the protein expression of $\mathrm{Cdc} 2$ and $\mathrm{Cdc} 25 \mathrm{c}$ in $\mathrm{J} 5$ cells. In addition, Tan-IIA arrested J5 cells at the $\mathrm{G} 2 / \mathrm{M}$ phase. It is not consistent with other studies that showed SMMC-7721 treated with Tan-IIA was arrested at the G0/G1 phase (15). ER stress-associated apoptotic molecules such as Calreticulin, caspase 12 and GADD153 are important key factors (23-25). Our results show that Hep-J5 cells treated with Tan-IIA increased the protein expression of calreticulin, caspase 12 and GADD153. Furthermore, the J5 cells pretreated with Z-VAD-FMK $(50 \mu \mathrm{M})$ decreased the cytotoxicity of Tan-IIA. One of the molecular mechanisms for Tan-IIA to inhibit Hep-J5 cells may be through upregulating the protein expression of caspase 12. Tan-IIA inhibited proliferation and induced apoptosis in hepatocellular carcinoma cell lines by a different pathway, such as decreasing Bcl-2 and increasing Bax expression (15), downregulating EGF and EGFR protein expression in SMMC-

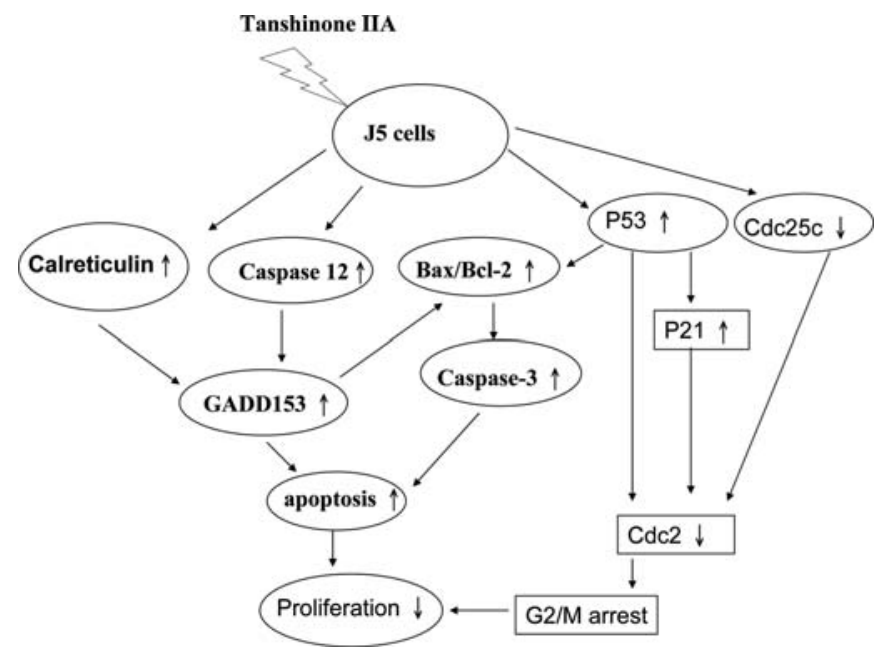

Figure 8. Proposed model for the molecular mechanism of Tanshinone IIA inhibition of the proliferation of J5 cells.

7721 (16) and by ROS-mediated p38 MAPK activation in HepG2 (17). Our results show that Tan-IIA inhibited proliferation and induced apoptosis in hepatocellular carcinoma $\mathrm{J} 5$ cells through up-regulating the protein expression of calreticulin, caspase 12 and GADD153. In Fig. 8 the proposed model of Tan-IIA inhibition of HCC J5 cells is reported for the first time.

\section{Acknowledgements}

This study was supported by grant TCRD98-17 from the Research Section of Buddhist Tzu Chi General Hospital, Hualien, Taiwan. This work was partially supported by the Chen-Han Foundation for Education.

\section{Reference}

1. Bosch FX, Ribes J, Cléries R and Díaz M: Epidemiology of hepatocellular carcinoma. Clin Liver Dis 9: 191-211, 2005.

2. Statistics of Causes of Death, 2007. Department of Health, Executive Yuan, Taipei, Taiwan, R.O.C, p34-46, 2008.

3. Leung TW and Johnson PJ: Systemic therapy for hepatocellular carcinoma. Semin Oncol 28: 514-520, 2001.

4. Oyadomari S and Mori M: Roles of CHOP/GADD153 in endoplasmic reticulum stress. Cell Death Differ 11: 381-389, 2004.

5. Che AJ, Zhang JY, Li CH, Chen XF, Hu ZD and Chen XG: Separation and determination of active components in Radix Salviae miltiorrhizae and its medicinal preparations by nonaqueous capillary electrophoresis. J Sep Sci 27: 569-575, 2004.

6. Zhou L, Zuo Z and Chow MS: Danshen: An overview of its chemistry, pharmacology, pharmacokinetics, and clinical use. J Clin Pharmacol 45: 1345-1359, 2005.

7. Lin R, Wang WR, Liu JT, Yang GD and Han CJ: Protective effect of tanshinone IIA on human umbilical vein endothelial cell injured by hydrogen peroxide and its mechanism. J Ethnopharmacol 108: 217-222, 2006.

8. Wang AM, Sha SH, Lesniak W and Schacht J: Tanshinone (Salviae miltiorrhizae extract) preparations attenuate aminoglycoside-induced free radical formation in vitro and ototoxicity in vivo. Antimicrob Agents Chemother 47: 1836-1841, 2003.

9. Jang SI, Kim HJ, Kim YJ, Jeong SI and You YO: Tanshinone IIA inhibits LPS-induced NF-kappaB activation in RAW 264.7 cells: possible involvement of the NIK-IKK, ERK1/2, p38 and JNK pathways. Eur J Pharmacol 542: 1-7, 2006. 
10. Li W, Li J, Ashok M, Wu R, Chen D, Yang L, Yang H, Tracey KJ, Wang P, Sama AE and Wang H: A cardiovascular drug rescues mice from lethal sepsis by selectively attenuating a late-acting proinflammatory mediator, high mobility group box 1 . J Immunol 78: 3856-3864, 2007.

11. Liu JJ, Lin DJ, Liu PQ, Huang M, Li XD and Huang RW: Induction of apoptosis and inhibition of cell adhesive and invasive effects by tanshinone IIA in acute promyelocytic leukemia cells in vitro. J Biomed Sci 13: 813-823, 2006.

12. Su CC and Lin YH: Tanshinone IIA inhibits human breast cancer cells through increased Bax to Bcl-xL ratios. Int J Mol Med 22: 357-361, 2008.

13. Su CC, Chen GW, Kang JC and Chan MH: Growth inhibition and apoptosis induction by tanshinone IIA in human colon adenocarcinoma cells. Planta Med 74: 1357-1362, 2008.

14. Chiu TL and Su CC: Tanshinone IIA induces apoptosis in human lung cancer A549 cells through the induction of reactive oxygen species and decreasing the mitochondrial membrane potential. Int J Mol Med 25: 231-236, 2010.

15. Yuan SL, Wei YQ, Wang XJ, Xiao F, Li SF and Zhang J: Growth inhibition and apoptosis induction of tanshinone IIA on human hepatocellular carcinoma cells. World J Gastroenterol 10: 2024-2028, 2004.

16. Zhai XM, He SX, Ren MD, Chen JH, Wang ZL, Han M and Hou HL: Effect of Tanshinone II A on expression of EGF and EGFR in hepatocellular carcinoma cell line SMMC-7721. Zhejiang Da Xue Xue Bao Yi Xue Ban. 38: 163-169, 2009.

17. Lee WY, Liu KW and Yeung JH: Reactive oxygen speciesmediated kinase activation by dihydrotanshinone in tanshinones-induced apoptosis in HepG2 cells. Cancer Lett 285: $46-57,2009$.
18. Mossman T: Rapid colorimetric assay for cellular growth and survival: application to proliferation and cytotoxicity assays. J Immunol Methods 65: 55-63, 1983.

19. Su CC and Lin YH: Tanshinone IIA down-regulates the protein expression of ErbB-2 and up-regulates TNF- $\alpha$ in colon cancer cells in vitro and in vivo. Int J Mol Med 22: 847-851, 2008.

20. Bradford MM: A rapid and sensitive method for the quantization of microgram quantities of protein using the principle of proteindye binding. Anal Biochem 72: 248-254, 1976.

21. Su CC, Chen GW and Lin JG: Growth inhibition and apoptosis induction by tanshinone I in human colon cancer Colo 205 cells. Int J Mol Med 22: 613-618, 2008

22. Lin SS, Huang HP, Yang JS, Wu JY, Hsia TC, Lin CC, Lin CW, Kuo CL, Gibson Wood W and Chung JG: DNA damage and endoplasmic reticulum stress mediated curcumin-induced cell cycle arrest and apoptosis in human lung carcinoma A-549 cells through the activation caspases cascade- and mitochondrialdependent pathway. Cancer Lett 272: 77-90, 2008

23. Obeid M, Tesniere A, Ghiringhelli F, Fimia GM, Apetoh L, Perfettini JL, Castedo M, Mignot G, Panaretakis T, Casares N, Metivier D, Larochette N, van Endert P, Ciccosanti F, Piacentini M, Zitvogel L and Kroemer G: Calreticulin exposure dictates the immunogenicity of cancer cell death. Nat Med 13: 54-61, 2007.

24. Clarke C and Smyth MJ: Calreticulin exposure increases cancer immunogenicity. Nat Biotechnol 25: 192-193, 2007.

25. Apetoh L, Ghiringhelli F and Zitvogel L: [Calreticulin dictates the immunogenicity of anti-cancer chemotherapy and radiotherapy]. Med Sci (Paris) 23: 257-258, 2007. 